\title{
UMA INTRODUÇÃO AO CONFORTO TERMO-AMBIENTAL DO COLÉGIO ESTADUAL SANTA GEMMA GALGANI, CURITIBA, PARANÁ, BRASIL
}

\author{
Daniela Biondi ${ }^{1}$, Angeline Martini ${ }^{2}$, Everaldo Marques Lima Neto ${ }^{3}$ \\ ${ }^{1}$ Universidade Federal do Paraná, Departamento de Ciências Florestais, Curitiba, Paraná, Brasil - dbiondi@ufpr.br \\ ${ }^{2}$ Universidade Federal do Paraná, Programa de Pós-Graduação em Engenharia Florestal, Curitiba, Paraná, Brasil - \\ martini.angeline@gmail.com \\ ${ }^{3}$ Universidade Estadual de Roraima, Departamento de Ciências Exatas e Agrárias, Rorainópolis, Roraima, Brasil - \\ everaldo.limaneto@gmail.com
}

Recebido para publicação: 30/07/2012 - Aceito para publicação: 10/09/2014

\begin{abstract}
Resumo
O objetivo desta pesquisa foi avaliar as condições de conforto térmico do Colégio Estadual Santa Gemma Galgani, Curitiba, PR comparando ambientes internos e externos em diferentes estações do ano. A análise do conforto térmico foi realizada através do índice PET. As coletas foram feitas no outono, inverno e primavera de 2011, em dois dias e em dois ambientes distintos. Em cada dia de coleta, foi instalado um equipamento dentro da sala de aula e outro na área externa (pátio), caracterizada como: ambiente 1 - área externa com mais de 90\% de impermeabilização e menos árvores; e ambiente 2 - área externa com menos de $30 \%$ de impermeabilização e mais árvores. A área do colégio possui $7.634,91 \mathrm{~m}^{2}$, sendo $36,56 \%$ de áreas permeáveis e $60,44 \%$ de impermeáveis. Nas três estações do ano, a temperatura do ar foi mais alta no pátio, com exceção do outono para o ambiente 1 e da primavera para o ambiente 2. Houve diferenças significativas nas condições de conforto entre os ambientes 1 e 2, indicando que as áreas são distintas pela permeabilidade e quantidade de vegetação. Conclui-se que, no geral, as salas de aula do colégio nas estações do outono, inverno e primavera apresentaram conforto térmico na maioria do período observado.

Palavras-chave: Índice PET; Termômetro de Globo; temperatura do ar; umidade relativa do ar.
\end{abstract}

\begin{abstract}
An introduction to thermal-environmental comfort state college St. Gemma Galgani, Curitiba, Parana, Brazil. The aim of this study was to evaluate the thermal comfort of the State College Santa Gemma Galgani, Curitiba, PR comparing internal and external environments in different seasons. The analysis of thermal comfort index was performed using PET. Collections were made in the fall, winter and spring of 2011 in two days and in two different environments. Every day a collect was installed equipment within the classroom and another in the outer area (outdoor), characterized as an environment 1 - outdoor area with more than $90 \%$ of waterproofing and fewer trees; and the environment 2 - external area under $30 \%$ waterproofing and more trees. The area of the college has $7634.91 \mathrm{~m}^{2}$ and $36.56 \%$ to $60.44 \%$ permeable areas and waterproof. In three seasons, the air temperature was higher in the courtyard, with the exception of autumn to the environment and a spring for the environment 2. There were significant differences in terms of comfort between locations 1 and 2, indicating that the areas are distinct permeability and the amount of vegetation. It is concluded that, overall, the classrooms of the college stations in the fall, winter and spring had thermal comfort for most of the observed period.

Keywords: PET index; Globe Thermometer; air temperature; relative humidity.
\end{abstract}

\section{INTRODUÇÃO}

Uma das funções da arquitetura é oferecer ao homem condições térmicas compatíveis ao conforto ambiental humano no interior dos edifícios, não importando as condições climáticas externas (BELTRAME; MOURA, 2011). Todavia, a intervenção humana, no ato da construção de seus edifícios,

FLORESTA, Curitiba, PR, v. 45, n. 2, p. 409 - 420, abr. / jun. 2015.

Biondi, D.; Martini, A.; Lima Neto, E. M.

ISSN eletrônico 1982-4688 / ISSN impresso 0015-3826 
altera as condições climáticas locais, das quais também depende a resposta térmica da edificação (RIBEIRO, 2007).

Gaudin e Bastos (2011) afirmam que a qualidade ambiental tem o objetivo de alcançar melhorias e/ou manter a característica do projeto de arquitetura, equipamentos, implantação ou construção, relativamente aos impactos da edificação no ambiente exterior e às condições de conforto, segurança e saúde dos usuários nos ambientes interiores da edificação.

Para assegurar a qualidade ambiental em áreas construídas, a ISO 14001 define diretrizes gerais, exigências e especificações para gestão da qualidade ambiental. Com isso, no setor de construção, um sistema de gestão pode otimizar a qualidade ambiental de uma edificação, promovendo a organização operacional e mantendo a sustentabilidade ambiental da edificação (REFERENCIAL TÉCNICO DE CERTIFICAÇÃO, 2007).

O conforto térmico encontra-se inserido no conforto ambiental, do qual também fazem parte o conforto visual (incluindo a psicodinâmica das cores), o conforto acústico e a qualidade do ar. Seus estudos têm ligação estreita com as áreas de engenharia e arquitetura, por serem elas as responsáveis pela concepção e criação dos ambientes nos quais o homem passa grande parte de sua vida (XAVIER, 1999).

Entende-se como conforto térmico o estado em que um indivíduo não tem vontade de mudar sua interação térmica com o meio. Essa neutralidade térmica é um ideal de comodidade, como também de adequação, pois colabora para a eficiência na realização das atividades (SCHMID, 2005).

Essas trocas térmicas relacionadas ao corpo humano podem acontecer por trocas secas (condução, radiação e convecção) ou troca úmida (evaporação), sendo que o fluxo de energia térmica ocorre sempre do corpo com maior para o de menor temperatura (FROTA; SCHIFFER, 2001). Roaf et al. (2009) definem essas trocas da seguinte maneira: convecção refere-se à perda térmica para o ar ou o ganho de calor do ar; radiação é a perda térmica direta para o entorno ou ganho de calor do entorno; condução é perda térmica direta ou ganho térmico das superfícies em contato com o corpo; evaporação refere-se à perda térmica para que ocorra a evaporação da umidade da pele.

Sabe-se ainda que a percepção humana do clima e a sensação de conforto térmico devem-se não só a fatores fisiológicos, mas também psicológicos e culturais (DI CLEMENTE, 2009). Segundo Roaf et al. (2009), o conforto térmico é uma resposta ao ambiente físico e ao estado psicológico do corpo, influenciado pela postura do indivíduo em relação ao ambiente que o cerca e suas experiências com ambientes térmicos.

Dois grupos de variáveis exercem maior influência no conforto térmico: as de natureza ambiental e as de natureza pessoal (LAMBERTS et al., 1997). Segundo os mesmos autores, as variáveis de natureza ambiental são a temperatura do ar, a temperatura radiante média, a umidade relativa do ar e a velocidade do vento. Já as variáveis de natureza pessoal são o tipo de atividade física realizada (representada pelo metabolismo) e o tipo de vestimenta (representada pelo seu isolamento térmico).

As escolas, independentemente de serem estaduais, municipais ou particulares, devem investir no tratamento paisagístico dos seus pátios e espaços livres. Essas áreas, quando bem planejadas, podem se tornar uma expansão das salas de aula ou um recurso educacional para as práticas de ensino e aprendizagem. Além disso, um tratamento paisagístico da área externa da escola não só melhora suas condições como também beneficia as salas de aula, proporcionando um maior conforto ambiental (BIONDI, 2008).

Sentir-se confortável é uma das melhores sensações dos seres humanos. Alguns estudos já comprovaram que condições desfavoráveis de conforto ambiental são causa de mau desempenho dos alunos. Se considerarmos que o conforto térmico e o ambiente interferem no aproveitamento didático dos alunos em sala de aula, torna-se importante fazer avaliação do ambiente construído, com a necessidade de investigação para melhorar a qualidade ambiental final do espaço arquitetônico (BELTRAME; MOURA, 2011).

Uma forma de buscar melhores condições de conforto amplamente divulgada é a utilização da vegetação. Silveira (1999) afirma que, em áreas cobertas por vegetação, as temperaturas são menores do que o entorno desprovido de massa vegetal, isso porque a vegetação diminui a absorção por radiação solar e, portanto, diminui a dissipação de calor por ondas longas.

Nas questões relativas ao desempenho térmico, Romero (2001) enfatiza que a vegetação apresenta menor capacidade calorífera e condutividade térmica do que os materiais dos edifícios e grande capacidade de absorção da radiação solar pelas folhas, resultando em menos reflexão (albedo baixo). 
Para Mahmoud (2011), o efeito das árvores no microclima ao longo do dia é devido à redução da passagem dos raios solares para o chão, proporcionando sombreamento a essa área. Já Abreu (2008) ressalta que é a evapotranspiração das plantas que exerce efeito muito positivo no clima urbano, pois esse processo tem a capacidade de absorver calorias, o que leva à diminuição da temperatura do microclima local nas horas de maior calor.

Em Curitiba, nos últimos anos, tem ocorrido um processo para delegar ao poder municipal a gestão do ensino básico, iniciando-se, assim a municipalização de algumas escolas estaduais. As escolas particulares são independentes e não participam desse processo. Até 1982, a rede pública do município contava com 63 prédios escolares estaduais e 64 prédios municipais, num total de 127 estabelecimentos. Visando definir critérios para o planejamento e implantação dos prédios das escolas da rede física estadual do Paraná, o Instituto de Desenvolvimento Educacional do Paraná normatizou os seguintes procedimentos: localização do terreno (acesso, proximidade de centros urbanos, serviços de água, esgoto, rede elétrica e telefônica, áreas de risco - morros -, outras proximidades - hospitais, sanatórios, indústrias - e outros); formação e composição geológica (aterros, rochosas, arenosas, topografia (depressões, barrancos, elevação), forma do terreno (quadrado ou retangular), áreas mínimas (pequenos - 2.000 a $4.000 \mathrm{~m}^{2}$; médios - 5.000 a $9.000 \mathrm{~m}^{2}$; grandes - acima de $10.000 \mathrm{~m}^{2}$ ), aquisição de terrenos (por compra ou doação), recomendações para implantação de unidades escolares (insolação, locação, vedação e acesso, movimento de terra, paisagismo, quadra de esportes, mastros, bancos, telefone público, pontes e abastecimento de água). Quanto ao paisagismo das unidades escolares, o procedimento previsto deve ser a preservação da área, dentro do possível, com a vegetação existente. Se não houver vegetação, prever sua implantação, para servir de proteção contra o sol excessivo, ventos fortes, ruídos e poluição (FUNDAÇÃO EDUCACIONAL DO ESTADO DO PARANÁ (FUNDEPAR), 2002).

Schaffer (2005), analisando a qualidade ambiental dos terrenos de 30 escolas estaduais da cidade de Curitiba, constatou que 20 unidades escolares (67\%) apresentaram áreas impermeáveis maiores que as permeáveis. As áreas permeáveis encontradas eram revestidas por vegetação (gramados, jardins, hortas, pomares) e por elementos rochosos sem juntas e com espaçamentos entre si, como pedriscos, quadras de areia e solo exposto. Já as áreas impermeáveis encontradas eram revestidas por elementos rochosos e cerâmicos agregados com massa de cal e cimento, ou justapostas sem espaçamentos entre si, como as construções, quadras esportivas pavimentadas, pisos de cimento e calçadas. A mesma autora enfatizou nas suas recomendações que a falta de conservação tanto das áreas permeáveis quanto das áreas impermeáveis dos terrenos das escolas poderia ser melhorada ambientalmente pela Secretaria de Educação, para melhor convívio entre as equipes pedagógicas, a direção, os funcionários, os professores e os alunos das escolas.

Partindo da fundamentação de que a aplicação da sustentabilidade ambiental nas escolas públicas implica principalmente a avaliação da qualidade da cobertura de áreas não edificadas e o uso e ocupação das áreas edificadas, considerou-se a seguinte hipótese para esta pesquisa: quanto maior a área permeável do terreno da unidade escolar e maior cobertura vegetal, maior será o conforto termoambiental das áreas edificadas. Sendo assim, o objetivo desta pesquisa foi fazer uma avaliação exploratória das condições de conforto térmico do Colégio Estadual Santa Gemma Galgani, Curitiba, PR, comparando ambientes internos e externos em diferentes estações do ano.

\section{MATERIAL E MÉTODOS}

A pesquisa foi realizada no Colégio Estadual Santa Gemma Galgani, situado no bairro

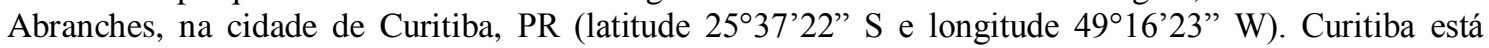
localizada no primeiro planalto, na região Sul do Brasil, ocupando uma área de $432,17 \mathrm{~km}^{2}$, com altitude de 934,6 metros acima do nível do mar (INSTITUTO DE PESQUISA E PLANEJAMENTO URBANO DE CURITIBA (IPPUC), 2011). De acordo com o último censo do Instituto Brasileiro de Geografia e Estatística (IBGE), de 2010, a população do município é de 1.851.215 habitantes (IBGE, 2012). O clima, segundo a classificação climática de Köppen, é do tipo Cfb, com clima subtropical (ou temperado) úmido, mesotérmico, sem estação seca, com verões frescos e invernos com geadas frequentes. Os ventos que predominam são de nordeste. As temperaturas médias do ar são de $19,7^{\circ} \mathrm{C}$ no verão e $13,4{ }^{\circ} \mathrm{C}$ no inverno. A precipitação média anual é de 1.419,91 mm, com um período de estiagem, não fixo, entre o outono e o inverno (IPPUC, 2011).

O Colégio Estadual Santa Gemma Galgani foi inaugurado em 1978 e atualmente funciona com

FLORESTA, Curitiba, PR, v. 45, n. 2, p. 409 - 420, abr. / jun. 2015. 
um total de 27 turmas, sendo alunos de ensino médio no período matutino e ensino fundamental no período vespertino (SECRETARIA DE EDUCAÇÃO DO ESTADO DO PARANÁ, 2012).

Para a análise do conforto térmico, foi utilizado o índice PET (Physiological Equivalent Temperature), calculado através do aplicativo computacional RayMan, software de livre acesso desenvolvido pelo Instituto de Meteorologia de Freiburg (MATZARAKIS et al., 2000).

O índice PET baseia-se na equação de balanço térmico do corpo humano, MEMI (Munich Energybalance Model for Individuals), em condições de estabilidade (HÖPPE, 1999). Segundo o mesmo autor, é definido como a temperatura fisiológica equivalente, em um determinado ambiente, à temperatura do ar de um ambiente interno de referência, no qual o balanço térmico do corpo humano mantém-se igual às condições de avaliação. Os valores padrão de referência são: umidade relativa de $50 \%$ a uma temperatura do ar de $20{ }^{\circ} \mathrm{C}$ (pressão parcial de vapor de água de $12 \mathrm{hPa}$ ); velocidade do ar de $0,1 \mathrm{~m} / \mathrm{s}$; temperatura radiante média igual à temperatura do ar; metabolismo de $80 \mathrm{~W}$; e vestimenta de 0,9 clo.

O cálculo do índice no software RayMan é possível com a entrada dos seguintes dados: atividade metabólica $(\mathrm{W})$, resistência térmica das roupas (clo), gênero, idade, peso $(\mathrm{kg})$ e altura $(\mathrm{m})$, além de dados microclimáticos de temperatura do ar $\left({ }^{\circ} \mathrm{C}\right)$, umidade relativa do ar $(\%)$, velocidade do $\mathrm{ar}(\mathrm{m} / \mathrm{s})$ e temperatura radiante média $\left({ }^{\circ} \mathrm{C}\right)$, sendo que as características físicas utilizadas do indivíduo padrão brasileiro e a atividade metabólica e resistência térmica das roupas são as mesmas do ambiente de referência.

Posteriormente foi elaborado um quadro para relacionar os valores bioclimáticos (índices) e a sensação humana, utilizada por Matzarakis et al. (1999), para determinar a sensação humana proporcionada pelos ambientes analisados (Tabela 1).

Tabela 1. Sensação térmica e nível de estresse térmico proporcionado pelo índice PET.

Table 1. Thermal sensation and level of heat stress provided by PET index.

\begin{tabular}{ccc}
\hline PET & Sensação térmica & Nível de estresse térmico \\
\hline $4{ }^{\circ} \mathrm{C}$ & Muito frio & Extremo estresse para o frio \\
$13{ }^{\circ} \mathrm{C}$ & Frio & Forte estresse para o frio \\
$18{ }^{\circ} \mathrm{C}$ & Pouco frio & Moderado estresse para o frio \\
$23{ }^{\circ} \mathrm{C}$ & Leve frio & Leve estresse para o frio \\
$29{ }^{\circ} \mathrm{C}$ & Confortável & Sem estresse térmico (conforto) \\
$35^{\circ} \mathrm{C}$ & Leve calor & Leve estresse para o calor \\
$41{ }^{\circ} \mathrm{C}$ & Pouco calor & Moderado estresse para o calor \\
$8{ }^{\circ} \mathrm{C}$ & Calor & Forte estresse para o calor \\
\hline
\end{tabular}

As variáveis monitoradas para o cálculo desse índice foram obtidas através do medidor de stress térmico, modelo TGD-400, da marca Instrutherm. Esse termômetro de globo digital calcula automaticamente o Índice de Bulbo Úmido Termômetro de Globo (IBUTG) interno e externo e indica separadamente as temperaturas de bulbo úmido, seco, globo, além da velocidade do vento. Obtendo-se a temperatura do globo por esse aparelho, foi possível determinar a temperatura radiante média, por meio da fórmula definida pela ISO 7726:

$$
T_{r m}=\left[(t g+273)^{4}+2,5 \times 10^{8} \times v_{a}^{0,6} \times(t g-t a)\right]^{\frac{1}{4}}-273
$$

em que: $\operatorname{Trm}=$ temperatura média radiante $\left({ }^{\circ} \mathrm{C}\right)$;

$\operatorname{tg}=$ temperatura do globo $\left({ }^{\circ} \mathrm{C}\right)$;

va $=$ velocidade do vento $(\mathrm{m} / \mathrm{s})$;

ta $=$ temperatura do $\operatorname{ar}\left({ }^{\circ} \mathrm{C}\right)$.

As coletas das variáveis meteorológicas foram realizadas ao longo do período letivo, nas estações de outono, inverno e primavera do ano de 2011. Para cada estação do ano, foram necessários dois dias de coleta, devido ao número de equipamentos (dois) e à existência de ambientes externos distintos. Os equipamentos foram mantidos a $1,50 \mathrm{~m}$ de altura, sendo que o período de coleta dos dados foi das 10:15 h às 16:00 h, com intervalo de monitoramento de 1 minuto, o que gerou um conjunto de 345 dados. 
Em cada dia de coleta (dois por estação do ano), foi instalado um equipamento dentro da sala de aula e outro na área externa adjacente. O equipamento da sala de aula foi colocado no centro dela, em períodos de aula, e o outro, da área externa, permaneceu na mesma direção que o equipamento da sala, passível de se observar pela janela. No entanto, para diminuir as interferências do meio, este equipamento ficou em uma posição equidistante, entre a parede da sala e o muro da escola.

Os ambientes externos selecionados para a realização da pesquisa apresentaram as seguintes características: ambiente 1 - área externa com mais de $90 \%$ de impermeabilização (pátio cimentado), com 8 árvores adultas plantadas em canteiros restritos; ambiente 2 - área externa com menos de $30 \%$ de impermeabilização (plantas rasteiras ou solo exposto), com mais de 12 árvores adultas (Figura 1).

Os dados de temperatura do ar, umidade relativa do ar e índice PET foram processados no programa Excel e transformados em médias a cada 15 minutos. Essas médias foram comparadas estatisticamente pelo teste $t$ de Student, que compara duas médias para definir se há diferença ou não entre elas.

Por terem sido coletados em dias e estações do ano diferentes, para possibilitar uma comparação dos dados, optou-se também por efetuar a subtração dos dados pareados, ou seja, valores da área externa menos os valores da sala de aula, em cada minuto do dia de coleta. Assim, obteve-se a diferença média das variáveis analisadas em cada situação, estação do ano e ambiente externo.

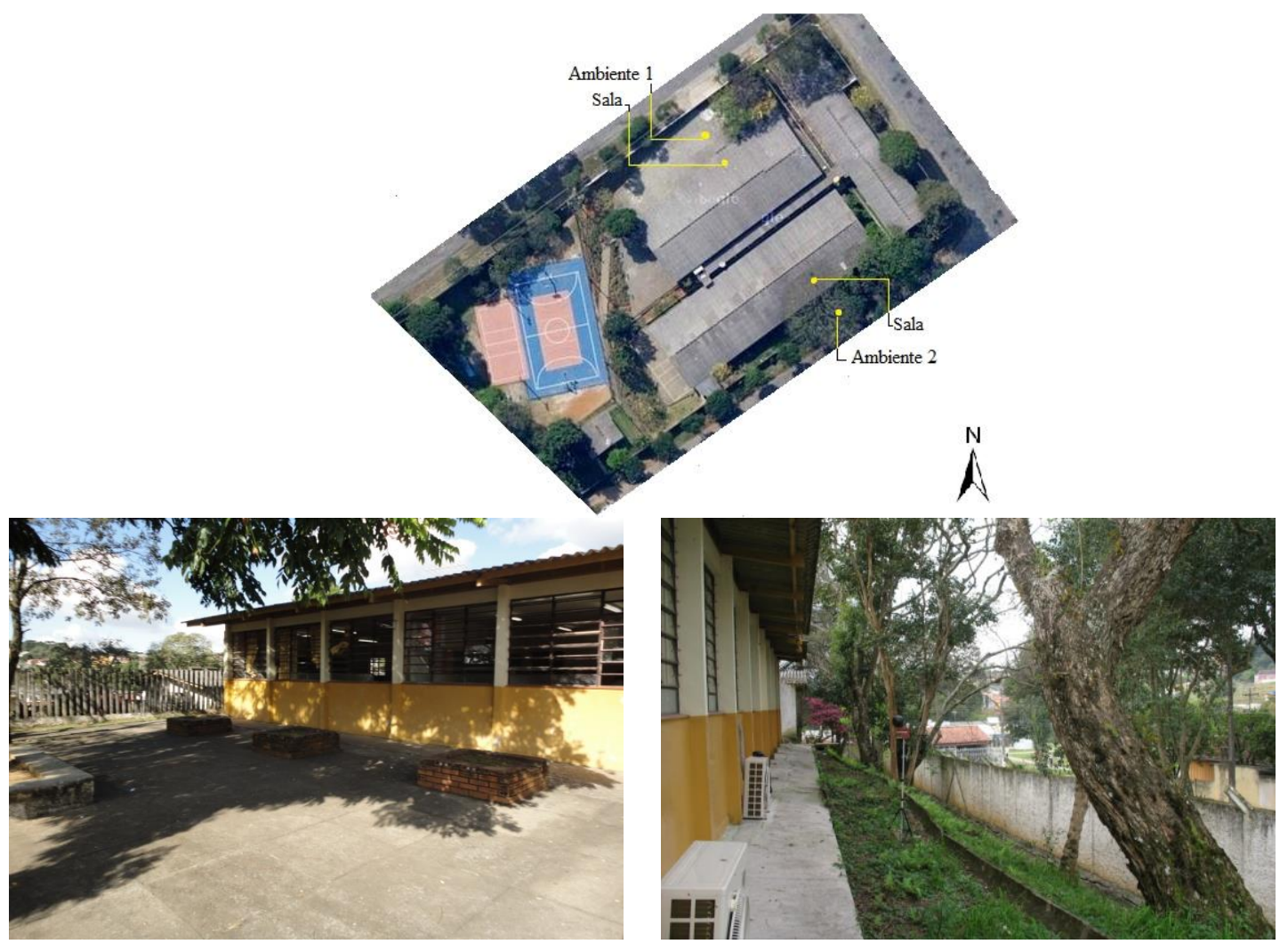

Figura 1. Localização e características dos ambientes selecionados - Ambiente 1 e Ambiente 2.

Figure 1. Location and characteristics of the selected environments - Environment 1 and Environment 2.

\section{RESULTADOS E DISCUSSÃO}

A instituição de ensino apresenta 7.634,91 $\mathrm{m}^{2}$ de área total, sendo 36,56\% de áreas permeáveis e $60,44 \%$ de área impermeável. Isso demonstra que o terreno está, em grande parte, comprometido por construções e pátios cimentados, restando pouco espaço para práticas ou alternativas consideradas sustentáveis, tais como horta, pomar e jardim. Esse resultado não é tão diferente do alcançado por Schaffer (2005), em estudo realizado em 30 colégios estaduais também em Curitiba, tendo sido

FLORESTA, Curitiba, PR, v. 45, n. 2, p. 409 - 420, abr. / jun. 2015.

Biondi, D.; Martini, A.; Lima Neto, E. M.

ISSN eletrônico 1982-4688 / ISSN impresso 0015-3826 
encontrado um percentual de $67 \%$ de áreas impermeáveis.

Beltrame e Moura (2011) afirmam que escolas cujas construções reúnem apenas concreto, pisos, madeiras e ferros deixam a desejar no que diz respeito a ambientes proporcionadores de boa qualidade para o estudo e o aprendizado.

\section{Temperatura do ar}

Os resultados do processamento dos dados de temperatura do ar, durante o período letivo da escola, mostram que há diferenças significativas entre as médias encontradas na área externa (pátio) e na sala de aula (Tabela 2). Como pode se observar, na primavera não houve diferença estatística significativa entre as médias de temperatura do ar do pátio e da sala de aula no ambiente com mais vegetação e área permeável (Ambiente 2).

No geral, ao longo das três estações do ano, a temperatura do ar foi mais alta no pátio, com exceção do outono para o ambiente mais impermeável e da primavera para o ambiente com mais vegetação arbórea.

Labaki et al. (2011) afirmam que a vegetação arbórea nos ambientes externos atenua a radiação solar incidente e tem um papel fundamental na redução das temperaturas do ar. Porém deve-se levar em conta a arquitetura das árvores, pois copas densas e baixas dificultam a circulação do vento sob elas, mantendo um ambiente úmido e quente, o que não permite bons níveis de conforto.

Tabela 2. Síntese dos valores de temperatura do $\operatorname{ar}\left({ }^{\circ} \mathrm{C}\right)$ e aplicação do teste $t$ entre as médias encontradas no pátio e na sala de aula.

Table 2. Synthesis of air temperature $\left({ }^{\circ} \mathrm{C}\right)$ and $\mathrm{t}$ test between the averages found in the courtyard and in the classroom.

\begin{tabular}{|c|c|c|c|c|c|c|c|c|c|c|}
\hline \multirow{2}{*}{$\begin{array}{l}\text { Estação do } \\
\text { ano }\end{array}$} & \multirow[b]{2}{*}{ Ambiente } & \multicolumn{4}{|c|}{ Pátio } & \multicolumn{4}{|c|}{ Sala de aula } & \multirow[b]{2}{*}{ teste $t$} \\
\hline & & $\begin{array}{c}\text { T } \\
\text { máx. }\end{array}$ & $\begin{array}{c}\mathbf{T} \\
\mathbf{m i n} .\end{array}$ & $\begin{array}{l}\text { Desvio } \\
\text { padrão }\end{array}$ & $\begin{array}{c}\text { T } \\
\text { média }\end{array}$ & $\begin{array}{c}\text { T } \\
\text { máx. }\end{array}$ & $\begin{array}{c}\mathbf{T} \\
\mathbf{m i n} .\end{array}$ & $\begin{array}{l}\text { Desvio } \\
\text { padrão }\end{array}$ & $\begin{array}{c}\text { T } \\
\text { média }\end{array}$ & \\
\hline \multirow[t]{2}{*}{ Outono } & 1 & 20,4 & 16,7 & 0,80 & 18,6 & 22,7 & 16,8 & 1,85 & 19,7 & $2,70 * *$ \\
\hline & 2 & 23,0 & 21,4 & 0,54 & 22,4 & 22,8 & 21,5 & 0,28 & 22,1 & $2,48 *$ \\
\hline \multirow[t]{2}{*}{ Inverno } & 1 & 24,4 & 22,2 & 0,48 & 23,3 & 23,4 & 20,6 & 0,94 & 22,3 & $4,31 * *$ \\
\hline & 2 & 27,1 & 25,0 & 0,58 & 26,3 & 23,6 & 21,6 & 0,51 & 22,8 & $22,07 * *$ \\
\hline \multirow[t]{2}{*}{ Primavera } & 1 & 30,9 & 26,0 & 1,58 & 28,6 & 27,3 & 22,6 & 1,60 & 24,8 & $7,99 * *$ \\
\hline & 2 & 22,2 & 18,9 & 1,00 & 20,8 & 21,8 & 20,1 & 0,53 & 21,0 & $0,66^{\mathrm{ns}}$ \\
\hline
\end{tabular}

probabilidade pelo teste t de Student.

\section{Umidade relativa do ar}

Os resultados da análise de umidade relativa do ar durante o período letivo da escola mostram que há diferenças significativas entre as médias de umidade relativa do ar encontradas na área externa (pátio) e na sala de aula (Tabela 3). Observa-se que as médias de umidade relativa do ar na sala de aula foram maiores do que as do pátio. Provavelmente, isso se deve à presença de pessoas na sala de aula, que aumenta a quantidade de superfície de água para a atmosfera. Segundo Soares e Batista (2004), a umidade atmosférica se refere à água, sob forma de vapor invisível, existente no ar, a qual se encontra misturada com os demais componentes da atmosfera. As fontes naturais de fornecimento de água para a atmosfera são as superfícies de água (oceanos, lagos e rios), o gelo e a neve, a superfície do solo e as superfícies dos vegetais e animais.

Com base na tabela 3, pode-se observar ainda que na primavera não houve diferença estatística significativa para os valores de umidade relativa do ar encontrados entre o pátio e a sala de aula no ambiente com mais vegetação arbórea e área permeável (Ambiente 2), assim como encontrado para a temperatura do ar.

\section{Diferenças de temperatura e umidade relativa do ar}

A diferença média de temperatura do ar e umidade relativa do ar entre a sala de aula e a área externa foi calculada separadamente para cada ambiente. A esse resultado foi aplicado o teste t, que constatou diferença estatística significativa entre os ambientes apenas na primavera. Nas estações de outono e inverno, essa diferença não foi estatisticamente significativa (Tabela 4). 
Tabela 3. Síntese dos valores de umidade relativa do ar (\%) e aplicação do teste $t$ entre as médias encontradas no pátio e na sala de aula.

Table 3. Summary of values of relative humidity (\%) and t test between the averages found in the courtyard and in the classroom.

\begin{tabular}{|c|c|c|c|c|c|c|c|c|c|c|}
\hline \multirow{2}{*}{$\begin{array}{l}\text { Estação do } \\
\text { ano }\end{array}$} & \multirow[b]{2}{*}{ Ambiente } & \multicolumn{4}{|c|}{ Pátio } & \multicolumn{4}{|c|}{ Sala de aula } & \multirow[b]{2}{*}{ teste $t$} \\
\hline & & $\begin{array}{c}\text { UR } \\
\text { máx. }\end{array}$ & $\begin{array}{l}\text { UR } \\
\text { min. }\end{array}$ & $\begin{array}{c}\text { Desvio } \\
\text { padrão }\end{array}$ & $\begin{array}{c}\text { UR } \\
\text { média }\end{array}$ & $\begin{array}{c}\text { UR } \\
\text { máx. }\end{array}$ & $\begin{array}{c}\text { UR } \\
\text { min. }\end{array}$ & $\begin{array}{c}\text { Desvio } \\
\text { padrão }\end{array}$ & $\begin{array}{c}\text { UR } \\
\text { média }\end{array}$ & \\
\hline \multirow[t]{2}{*}{ Outono } & 1 & 64,6 & 52,5 & 3,07 & 58,3 & 69,1 & 54,8 & 3,08 & 60,8 & $2,80 * *$ \\
\hline & 2 & 75,2 & 61,9 & 4,32 & 66,8 & 76,1 & 69,6 & 1,88 & 72,1 & $5,40 * *$ \\
\hline \multirow[t]{2}{*}{ Inverno } & 1 & 53,7 & 47,6 & 1,65 & 50,8 & 58,0 & 53,5 & 1,20 & 55,7 & $11,53 * *$ \\
\hline & 2 & 43,4 & 34,7 & 3,03 & 39,7 & 55,4 & 47,9 & 2,20 & 51,2 & $14,80 * *$ \\
\hline \multirow[t]{2}{*}{ Primavera } & 1 & 52,7 & 38,3 & 5,19 & 46,8 & 64,4 & 47,1 & 6,13 & 57,8 & $6,55 * *$ \\
\hline & 2 & 82,9 & 71,8 & 3,25 & 77,0 & 81,0 & 76,6 & 1,23 & 78,2 & $1,73^{\mathrm{ns}}$ \\
\hline
\end{tabular}

Tabela 4. Aplicação do teste $\mathrm{t}$ nas diferenças médias de temperatura do ar $\left({ }^{\circ} \mathrm{C}\right)$ e umidade relativa do ar (\%) encontradas nos ambientes.

Table 4. $\mathrm{T}$ test differences in mean temperature $\left({ }^{\circ} \mathrm{C}\right)$ and relative humidity $(\%)$ found in the environments.

\begin{tabular}{|c|c|c|c|c|c|c|}
\hline \multirow[b]{2}{*}{$\begin{array}{l}\text { Estação do } \\
\text { ano }\end{array}$} & \multicolumn{3}{|c|}{ Temperatura do ar } & \multicolumn{3}{|c|}{ Umidade relativa do ar } \\
\hline & $\begin{array}{c}\text { Média } \\
\text { Ambiente 1 }\end{array}$ & $\begin{array}{c}\text { Média } \\
\text { Ambiente 2 }\end{array}$ & test $t$ & $\begin{array}{c}\text { Média } \\
\text { Ambiente 1 }\end{array}$ & $\begin{array}{c}\text { Média } \\
\text { Ambiente 2 }\end{array}$ & teste $t$ \\
\hline Outono & $1,1^{+}$ & 0,3 & $0,28^{\mathrm{ns}}$ & 2,4 & 5,3 & $0,22^{\mathrm{ns}}$ \\
\hline Inverno & 1,0 & 3,5 & $0,84^{\mathrm{ns}}$ & 4,9 & 11,6 & $1,21^{\mathrm{ns}}$ \\
\hline Primavera & 3,7 & $0,2^{+}$ & $2,02 *$ & 11,0 & 1,3 & $1,44^{\mathrm{ns}}$ \\
\hline
\end{tabular}

Observa-se na tabela 4 que, no ambiente mais impermeabilizado, a diferença média de temperatura do ar entre a sala e o pátio foi maior na primavera, alcançando $3,7{ }^{\circ} \mathrm{C}$. Já no outono, essa diferença foi de $1,1^{\circ} \mathrm{C}$, porém os valores mais elevados foram encontrados na sala de aula e não no pátio. Isso evidencia o efeito da área do pátio com cimento na temperatura do ar da sala de aula.

No ambiente com mais vegetação arbórea, a maior diferença entre as médias de temperatura do ar foi encontradas no inverno $\left(3,5{ }^{\circ} \mathrm{C}\right)$, sendo as temperaturas do ar mais elevadas no lado externo. $\mathrm{Na}$ primavera, foi verificada temperatura média do ar mais elevada no interior da sala. Segundo Higueras (2006), a temperatura do ar no entorno da vegetação se reduz em uma quantidade equivalente ao calor latente para evaporar a água transpirada.

Ao longo do ano letivo, em todas as estações, as médias de umidade relativa do ar foram mais altas no interior das salas de aula. Entretanto, para essa variável não foram encontradas diferenças estatísticas significativas entre os ambientes (Tabela 4).

Nota-se que, no ambiente mais impermeabilizado, a diferença média de umidade relativa do ar entre a sala de aula e o pátio foi maior na primavera, alcançando $11 \%$. Já no ambiente com mais vegetação arbórea, a maior diferença entre as médias de umidade relativa do ar foram encontradas no inverno (11,6\%). Embora estatisticamente não significativa, a diferença de umidade relativa do ar entre os ambientes é alta, no inverno e na primavera. No inverno, a diferença de umidade relativa do ar entre a sala e o ambiente com mais vegetação arbórea mostra-se maior, ao contrário do que ocorre na primavera. Nesta estação, a diferença de umidade relativa do ar entre a sala de aula e o ambiente mais impermeabilizado é maior.

A justificativa para não encontrar diferença significativa entre os ambientes pode estar nas características do dia de análise, que não foram semelhantes. No entanto, sabe-se que as espécies vegetais, devido as suas funções fisiológicas durante a fotossíntese, liberam umidade ao ambiente (HIGUERAS, 2006).

FLORESTA, Curitiba, PR, v. 45, n. 2, p. 409 - 420, abr. / jun. 2015.

Biondi, D.; Martini, A.; Lima Neto, E. M.

ISSN eletrônico 1982-4688 / ISSN impresso 0015-3826

DOI: $10.5380 /$ rf.v45i2.16796 


\section{Índice de conforto térmico}

Os resultados para o índice de conforto térmico durante o período letivo da escola mostram que há diferenças, em todas as situações, entre as médias do índice encontradas na área externa (pátio) e na sala de aula (Tabela 5).

Tabela 5. Síntese dos índices PET $\left({ }^{\circ} \mathrm{C}\right)$ encontrado no pátio e na sala de aula.

Table 5. Synthesis of PET index $\left({ }^{\circ} \mathrm{C}\right)$ found in the courtyard and in the classroom.

\begin{tabular}{|c|c|c|c|c|c|c|c|c|c|}
\hline \multirow{2}{*}{$\begin{array}{l}\text { Estação do } \\
\text { ano }\end{array}$} & \multirow[b]{2}{*}{ Ambiente } & \multicolumn{4}{|c|}{ Pátio } & \multicolumn{4}{|c|}{ Sala de aula } \\
\hline & & $\begin{array}{l}\text { PET } \\
\text { máx. }\end{array}$ & $\begin{array}{l}\text { PET } \\
\text { min. }\end{array}$ & $\begin{array}{c}\text { Desvio } \\
\text { padrão }\end{array}$ & $\begin{array}{l}\text { PET } \\
\text { média }\end{array}$ & $\begin{array}{l}\text { PET } \\
\text { máx. }\end{array}$ & $\begin{array}{l}\text { PET } \\
\text { min. }\end{array}$ & $\begin{array}{c}\text { Desvio } \\
\text { padrão }\end{array}$ & $\begin{array}{c}\text { PET } \\
\text { média }\end{array}$ \\
\hline \multirow[t]{2}{*}{ Outono } & 1 & 29,1 & 18,5 & 3,53 & 24,3 & 23,1 & 16,1 & 2,06 & 19,3 \\
\hline & 2 & 25,8 & 21,6 & 0,88 & 23,1 & 22,3 & 20,9 & 0,32 & 21,5 \\
\hline \multirow[t]{2}{*}{ Inverno } & 1 & 30,8 & 22,1 & 2,06 & 25,2 & 23,2 & 19,1 & 1,36 & 21,3 \\
\hline & 2 & 31,5 & 24,5 & 1,72 & 26,9 & 23,1 & 21,1 & 0,56 & 22,2 \\
\hline \multirow[t]{2}{*}{ Primavera } & 1 & 37,2 & 30,0 & 2,35 & 33,6 & 26,8 & 21,9 & 1,64 & 24,3 \\
\hline & 2 & 21,1 & 17,6 & 1,03 & 19,5 & 21,7 & 19,9 & 0,57 & 20,8 \\
\hline
\end{tabular}

Com base na tabela 5, pode-se observar que, no geral, o índice de conforto térmico foi maior no pátio, com exceção da primavera, onde o ambiente com mais vegetação arbórea (Ambiente 2) apresentou índices menores do que na sala de aula.

Segundo Labaki et al. (2011), os agrupamentos arbóreos exercem influência numa escala maior do que uma única árvore. Ou seja, a disposição de elementos arbóreos pode aumentar a capacidade de redução da temperatura do ar e a atenuação da radiação solar incidente, bem como intensificar as sensações de conforto térmico ao usuário num determinado raio.

A diferença média do índice PET entre a sala de aula e a área externa foi calculada separadamente para cada ambiente e em cada estação (Tabela 6). No ambiente mais impermeabilizado (Ambiente 1), a diferença média do índice PET entre a sala e o pátio foi maior na primavera, alcançando $9,36{ }^{\circ} \mathrm{C}$. Já no inverno, essa diferença foi de $3,84^{\circ} \mathrm{C}$. Em todos os casos, no ambiente $1 \mathrm{o}$ índice foi maior no pátio.

No ambiente com mais vegetação (Ambiente 2), a maior diferença entre as médias do índice PET foi encontrada no inverno $\left(4,63{ }^{\circ} \mathrm{C}\right)$, sendo os valores mais elevados encontrados no lado externo. A primavera foi a única estação em que o índice PET apresentou médias mais elevadas no interior da sala de aula.

Tabela 6. Diferenças médias do índice PET encontradas nos ambientes.

Table 6. T test the mean differences found in the PET index environments.

\begin{tabular}{lcc}
\hline Estação do ano & $\begin{array}{c}\text { Média } \\
\text { Ambiente 1 }\end{array}$ & $\begin{array}{c}\text { Média } \\
\text { Ambiente 2 }\end{array}$ \\
\hline Outono & 4,96 & 1,56 \\
Inverno & 3,84 & 4,63 \\
Primavera & 9,36 & $1,31^{+}$ \\
\hline
\end{tabular}

De maneira geral, ao longo do período letivo, as condições de conforto térmico no interior das salas de aula do Colégio Santa Gemma Galgani foram satisfatórias. Durante o outono, a sala com exposição noroeste apresentou um desconforto "leve por frio" durante a manhã. Na primavera, essa mesma sala apresentou desconforto "leve por calor" durante a tarde (Tabela 7). Embora Soares e Batista (2007) afirmem que as faces voltadas para o noroeste recebem mais energia e consequentemente mais calor, esse efeito pode ser alterado devido a condições urbanas, tais como posição e altura das construções.

Com base na tabela 7, observa-se que, durante o período do outono, as salas de aula apresentaram conforto térmico na maior parte do tempo (80,4\%) e condição de "leve frio" em 17,4\% do tempo. Nessa estação, o pátio apresentou as seguintes condições: $56,5 \%$ com "leve calor", $41,6 \%$ com "confortável" e 2,2\% com "pouco calor".

No inverno, nas salas de aula, novamente foi encontrada condição de conforto térmico na maior 
parte do tempo $(95,7 \%)$. Já na área externa, encontraram-se $80,4 \%$ para "leve calor", $10,9 \%$ para "confortável" e 8,7\% para "pouco calor". O pátio do Ambiente 2 no inverno apresentou, em 100\% do período, índices de "leve calor" a "pouco calor".

$\mathrm{Na}$ primavera, as salas de aula apresentaram condição de conforto térmico em $65,2 \%$ do tempo e "leve calor" em 34,8\%. No pátio, foi encontrado o índice "confortável" em 47,8\% do tempo, "pouco calor" em 32,6\%, "calor" em 17,4\% e "leve frio" em 2,2\%. Tanto o pátio como a sala de aula do Ambiente 2, nessa estação, apresentaram 100\% do índice "confortável". Esse resultado demonstra a influência da maior quantidade de área permeável e vegetação arbórea no local. Paula (2004) afirma que o sombreamento de área externa com vegetação pode trazer uma contribuição significativa para o conforto térmico em ambientes internos.

Tabela 7. Média dos índices PET nos ambientes.

Table 7. Average of PET index in the environments.

\begin{tabular}{|c|c|c|c|c|c|c|c|c|c|c|c|c|}
\hline \multirow{3}{*}{ Intervalo } & \multicolumn{4}{|c|}{ Outono } & \multicolumn{4}{|c|}{ Inverno } & \multicolumn{4}{|c|}{ Primavera } \\
\hline & \multicolumn{2}{|c|}{ Ambiente 1} & \multicolumn{2}{|c|}{ Ambiente 2} & \multicolumn{2}{|c|}{ Ambiente 1} & \multicolumn{2}{|c|}{ Ambiente 2} & \multicolumn{2}{|c|}{ Ambiente 1} & \multicolumn{2}{|c|}{ Ambiente 2} \\
\hline & Pátio & Sala & Pátio & Sala & Pátio & Sala & Pátio & Sala & Pátio & Sala & Pátio & Sala \\
\hline $10: 30$ & 25,4 & 16,1 & 24,0 & 20,9 & 22,9 & 19,2 & 27,6 & 21,1 & 30,0 & 22,4 & 17,6 & 19,9 \\
\hline $10: 45$ & 26,8 & 16,8 & 25,8 & 21,6 & 26,2 & 19,1 & 31,1 & 21,8 & 30,2 & 21,9 & 18,1 & 20,0 \\
\hline 11:00 & 26,2 & 17,1 & 23,1 & 21,9 & 25,7 & 19,7 & 31,5 & 22,3 & 30,8 & 22,3 & 18,2 & 20,1 \\
\hline $11: 15$ & 26,0 & 17,6 & 21,9 & 22,1 & 25,0 & 19,9 & 29,8 & 22,4 & 31,0 & 22,0 & 18,2 & 20,2 \\
\hline $11: 30$ & 27,7 & 17,7 & 21,9 & 22,3 & 26,9 & 20,4 & 26,8 & 21,6 & 31,6 & 22,3 & 18,4 & 20,2 \\
\hline $11: 45$ & 28,9 & 18,0 & 22,1 & 21,7 & 25,9 & 20,3 & 26,0 & 21,5 & 31,7 & 22,7 & 18,0 & 20,2 \\
\hline $12: 00$ & 28,8 & 18,4 & 22,2 & 21,5 & 28,3 & 20,5 & 26,2 & 21,6 & 31,9 & 22,9 & 19,0 & 20,3 \\
\hline $12: 15$ & 23,4 & 18,0 & 22,6 & 21,2 & 26,3 & 20,4 & 26,7 & 21,6 & 33,2 & 23,2 & 19,3 & 20,4 \\
\hline $12: 30$ & 27,1 & 17,6 & 22,7 & 21,2 & 25,1 & 20,4 & 26,6 & 21,9 & 32,8 & 23,4 & 19,2 & 20,5 \\
\hline $12: 45$ & 25,0 & 17,7 & 22,9 & 21,2 & 23,7 & 20,8 & 26,4 & 21,9 & 33,1 & 23,6 & 19,4 & 20,6 \\
\hline $13: 00$ & 28,2 & 17,9 & 23,1 & 21,2 & 24,7 & 20,5 & 26,3 & 21,9 & 31,6 & 23,9 & 19,5 & 20,6 \\
\hline $13: 15$ & 29,1 & 18,2 & 23,6 & 21,2 & 27,2 & 20,6 & 26,5 & 21,9 & 36,4 & 24,4 & 20,1 & 20,7 \\
\hline $13: 30$ & 26,8 & 18,9 & 23,9 & 21,2 & 30,8 & 21,6 & 26,6 & 22,1 & 34,5 & 24,6 & 19,7 & 20,7 \\
\hline $13: 45$ & 25,3 & 20,1 & 23,6 & 21,3 & 25,8 & 22,5 & 26,8 & 22,4 & 34,0 & 24,8 & 19,4 & 20,9 \\
\hline $14: 00$ & 23,1 & 20,5 & 23,3 & 21,3 & 25,3 & 22,7 & 26,3 & 22,5 & 37,2 & 25,1 & 19,3 & 20,9 \\
\hline $14: 15$ & 21,2 & 20,8 & 23,4 & 21,4 & 25,6 & 22,8 & 27,0 & 22,6 & 36,2 & 25,5 & 19,5 & 21,0 \\
\hline $14: 30$ & 22,1 & 20,9 & 23,4 & 21,5 & 22,3 & 22,6 & 26,6 & 22,8 & 36,6 & 25,7 & 20,8 & 21,2 \\
\hline $14: 45$ & 20,9 & 21,5 & 23,2 & 21,5 & 22,6 & 22,5 & 26,2 & 23,0 & 33,0 & 25,8 & 20,8 & 21,4 \\
\hline $15: 00$ & 20,8 & 21,6 & 23,3 & 21,6 & 25,8 & 22,8 & 25,9 & 23,1 & 35,4 & 25,9 & 20,9 & 21,4 \\
\hline $15: 15$ & 19,5 & 21,9 & 23,0 & 21,6 & 25,1 & 22,8 & 25,9 & 22,9 & 33,2 & 26,2 & 19,9 & 21,4 \\
\hline $15: 30$ & 18,5 & 22,0 & 22,9 & 21,6 & 23,0 & 22,9 & 25,5 & 22,8 & 37,0 & 26,4 & 20,5 & 21,6 \\
\hline $15: 45$ & 19,0 & 22,2 & 22,7 & 21,6 & 22,1 & 22,8 & 24,8 & 22,8 & 36,8 & 26,7 & 21,1 & 21,7 \\
\hline $16: 00$ & 19,0 & 23,1 & 21,6 & 21,6 & 23,1 & 23,2 & 24,5 & 22,7 & 35,6 & 26,8 & 20,6 & 21,7 \\
\hline Média & 24,3 & 19,3 & 23,1 & 21,5 & 25,2 & 21,3 & 26,9 & 22,2 & 33,6 & 24,3 & 19,5 & 20,8 \\
\hline \multicolumn{13}{|l|}{ Legenda: } \\
\hline 15 & o & & $25-0$ & netrave & $23-29$ & Dere & & $29-35^{\circ} \mathrm{C}$ & ouco calor & & $35-411^{\circ} \mathrm{C}$ & alor \\
\hline
\end{tabular}

É notória a diferença de conforto térmico entre o pátio e a sala de aula (Tabela 7). O pátio, na maioria das estações, foi sempre mais quente do que a sala, necessitando, porém, de tratamento paisagístico para melhorar não só o aspecto ecológico como também o estético. Embora os alunos permaneçam maior tempo nas salas de aula, os pátios também devem oferecer conforto para as atividades recreativas e de descanso.

Biondi (2008) recomenda arborização ou ajardinamento nas áreas de convivência dos estudantes, para tornar o ambiente mais agradável e cativante. A autora enfatiza a importância de aproveitar as áreas permeáveis das escolas públicas a fim de melhorar o conforto ambiental, tais como: nas divisas das escolas, para proporcionar maior isolamento acústico (das ruas e casas que circundam a escola); nos acessos das escolas, direcionando veículos e pedestres ao destino desejado; nos estacionamentos, para fornecimento de sombra e beleza local; próximo às edificações, para servir de proteção à insolação e

FLORESTA, Curitiba, PR, v. 45, n. 2, p. 409 - 420, abr. / jun. 2015.

Biondi, D.; Martini, A.; Lima Neto, E. M.

ISSN eletrônico 1982-4688 / ISSN impresso 0015-3826 
ventos, proporcionando um conforto aos recintos da escola; na fachada da escola, para embelezar e valorizar a instituição; nas grandes áreas sem uso imediato, destinadas à ampliação da escola, com formação de pomar, bosque com árvores nativas da região, com possibilidade de esse local ser utilizado tanto para recreação como para práticas pedagógicas.

Embora os resultados mais expressivos desta pesquisa tenham sido para o índice confortável nas salas de aula, é interessante mostrar o que acontece com as pessoas quando ocorre o desconforto, tanto para o frio como para o calor.

Oliveira (2006) complementa dizendo que o aparecimento de doenças devido ao frio está diretamente relacionado com a intensidade do estresse térmico. Sob condições moderadas, constata-se apenas um desconforto térmico, no entanto, com situações de estresse térmico leve, logo surgem os efeitos psicológicos e a diminuição do desempenho. Com o desconforto por elevada temperatura do ar em sala de aula, os alunos acabam por perder o interesse nas aulas, pedindo frequentemente ao professor para sair e tomar água ou ir para o intervalo antes do período normal.

\section{CONCLUSÃO}

- Com os resultados obtidos, foi possível verificar a hipótese de que área permeável do terreno da unidade escolar e a cobertura vegetal influenciaram o comportamento das variáveis ambientais temperatura e umidade relativa do ar e, consequentemente, proporcionaram maior conforto termoambiental nas áreas edificadas. Ressalte-se, no entanto, que existem outros fatores que podem influenciar no conforto térmico e que não foram abordados nesta pesquisa. Além disso, a abordagem utilizada permite a determinação de resultados preliminares que poderão servir para embasar novas pesquisas com maior detalhamento e especificidade.

- Em geral, as condições de conforto térmico das salas de aula do Colégio Estadual Santa Gemma Galgani, Curitiba, PR, nas estações outono, inverno e primavera, apresentaram índice PET "confortável" (18 a $\left.23{ }^{\circ} \mathrm{C}\right)$ em mais de $65 \%$ do período observado.

- O pátio do colégio foi, na maioria das vezes, o ambiente que apresentou maior período de tempo com índice PET de "leve calor" a "calor", indicando desconforto térmico.

- Nas três estações do ano (outono, inverno e primavera), somente a sala de aula adjacente ao Ambiente 2, com maior área permeável e cobertura vegetal, apresentou o índice PET "confortável" em praticamente $100 \%$ do período de análise.

\section{AGRADECIMENTOS}

Agradecemos à Fundação Araucária de Apoio ao Desenvolvimento Científico e Tecnológico do Paraná, pelo financiamento desta pesquisa.

\section{REFERÊNCIAS}

ABREU, L. V. de. Avaliação da escala de influência da vegetação no microclima por diferentes espécies arbóreas. 154 f. Dissertação (Mestrado em Engenharia Civil) - Faculdade de Engenharia Civil, Universidade Estadual de Campinas, Campinas, 2008.

BELTRAME, M. B.; MOURA, G. R. S. Edificações escolares: infraestrutura necessária ao processo de ensino e aprendizagem escolar. Disponível em: <http://www.unioeste.br/prppg/mestrados/letras/revistas /travessias/ed_006/EDUCA\%C7AO/PDF/EDIFICA\%C7\%D5ES\%20ESCOLARES.pdf>. Acesso em: 08/02/2011.

BIONDI, D. Arborização urbana aplicada à educação ambiental nas escolas. Curitiba, 2008. 120 p.

DI CLEMENTE, M. A. Influência da vegetação como elemento modificador do conforto térmico da ambiência urbana da cidade de Anápolis, GO. 150 f. Dissertação (Mestrado em Sociedade, Tecnologia e Meio Ambiente) - Centro Universitário de Anápolis, UniEvangélica, Anápolis/GO, 2009.

FROTA, A. B.; SCHIFFER, R. S. Manual de Conforto Térmico. 5. ed. São Paulo: Studio Nobel, 2001. $243 \mathrm{p}$. 
FUNDAÇÃO EDUCACIONAL DO ESTADO DO PARANÁ (FUNDEPAR). Curitiba - Divisão de Estudos e Projetos e divisão da Rede Física, 2002. Legislação e Normas para a escolha de terrenos e construção de prédios escolares.

GAUDIN, T. C. F. Q.; BASTOS, L. E. G. Alta qualidade ambiental em projetos de edificações escolares. Disponível em: <http://www.revival-eu.net/docs/Lycee\%20ENCAC2007_ARTIGO_ GAUDIN_BASTOS.pdf >. Acesso em: 05/02/2011.

HIGUERAS, E. Urbanismo bioclimático. Barcelona: Gustavo Gili, 2006, 241 p.

HÖPPE, P. The physiological equivalent temperature: a universal index for the biometeorological assessment of the thermal environment. International Journal of Biometeorology, n. 43, p. 71 - 75, 1999.

INSTITUTO BRASILEIRO DE GEOGRAFIA E ESTATÍSTICA (IBGE). Censo Demográfico 2010 Resultados do universo INSTITUTO BRASILEIRO DE GEOGRAFIA E ESTATÍSTICA (IBGE). Cidades. Disponível em: <http://www.ibge.gov.br/cidadesat/topwindow.htm?1>. Acesso em: 14/06/2012.

INSTITUTO DE PESQUISA E PLANEJAMENTO URBANO DE CURITIBA (IPPUC). Desenvolvimento sustentável: Indicadores de sustentabilidade de Curitiba - 2010. Curitiba: IPPUC, $2011.77 \mathrm{p}$.

INTERNACIONAL ORGANIZATION FOR STARDARDIZATION (ISO). Ergonomics of the thermal environment - instruments of measuring physycal quantities, ISO 7726. Switzerland, 1998.

LABAKI, L. C.; SANTOS, R. F.; BARTHOLOMEI, C. L. B.; ABREU, L. V. Vegetação e conforto térmico em espaços urbanos abertos. Fórum Patrimônio: Ambiente Construído e Patrimônio Sustentável (UFMG. Online), v. 5, p. 2, 2011.

LAMBERTS, R.; DUTRA, L.; PEREIRA, F. O. R. Eficiência energética na arquitetura. São Paulo: PW, 1997. $192 \mathrm{p}$.

MAHMOUD, A. H. A. Analysis of the microclimatic and human comfort conditions in an urban park in hot and arid regions. Building and Environment, Oxford, v. 46, p. 2641 - 2656, 2011.

MATZARAKIS, A.; MAYER, H.; IZIOMON, M. G. Applications of a universal thermal index: physiological equivalent temperature. International Journal of Biometeorology, Ohio, v. 43, n. 2, p. 76 - 84, 1999.

MATZARAKIS, A.; RUTZ, F.; MAYER, H. Estimation and calculation of the mean radiant temperature within urban structures. In: DEAR, R. J. de; KALMA, J. D.; OKE, T. R.; AULICIEMS, A. (Eds.). Biometeorology and Urban Climatology at the Turn of the Millenium. Sydney: WMO/TD, 2000, p. 273 - 278.

OLIVEIRA, A. V. F. M. de. Estudo de ambientes térmicos frios: desenvolvimentos experimentais e avaliação de condições de trabalho. 353 f. Tese (Doutorado em Ciências de Engenharia Mecânica) Faculdade de Ciências e Tecnologia de Coimbra. Coimbra, 2006.

PAULA, R. Z. R. A influência da vegetação no conforto térmico do ambiente construído. 119 f. Dissertação (Mestrado em Engenharia Civil) - Programa de Pós-Graduação em Engenharia Civil, Universidade Estadual de Campinas, Campinas, SP, 2004.

REFERENCIAL TÉCNICO DE CERTIFICAÇÃO - Edifícios do setor de serviços - Processo AQUA Escritórios - Edifícios escolares. Outubro/2007. Disponível em: <http://www.processoaqua.com.br/ pdf/RT-Hoteis-V0-Preliminar-junho2008.pdf>. Acesso em: 05/02/2011.

RIBEIRO, G. Conforto ambiental, sustentabilidade, tecnologia e meio ambiente: estudo de caso hospital Sarah Kubitschek - Brasília. III FÓRUM DE PESQUISA FAU. MACKENZIE I, 2007. Disponível em: <http://www.mackenzie.br/fileadmin/Graduacao/FAU/Publicacoes/PDF_IIIForum_a/ MACK_III_FORUM_GISLENE_RIBEIRO.pdf >. Acesso em: 08/02/2011. 
ROAF, S.; CRICHTON, D.; NICOL, F. A adaptação de edificações e cidades às mudanças climáticas. Tradução: Alexandre Salvaterra. Porto Alegre: Bookman, 2009. 384 p.

ROMERO, M. A. B. Arquitetura bioclimática do espaço público. Brasília: Editora da UnB, 2001. 226 p.

SCHAFFER, M. Análise da qualidade ambiental dos terrenos das escolas estaduais no município de Curitiba, PR. 201 f. Dissertação (Mestrado em Ciências do Solo) - Universidade Federal do Paraná, Curitiba, 2005.

SCHMID, A. L. A ideia de conforto: reflexões sobre o ambiente construído. Curitiba: Pacto Ambiental, 2005. $338 \mathrm{p}$.

SECRETARIA DE EDUCAÇÃO DO ESTADO DO PARANÁ. Colégio Estadual Santa Gemma Galgani. Disponível em: <http://www.ctasantagemma.seed.pr.gov.br/modules/conteudo/conteudo.php? conteudo=1> Acesso em: 13/05/2012.

SILVEIRA, A. L. R. C. Diretrizes de projeto para construção de prédios escolares em Teresina, PI. 205 f. Dissertação (Mestrado em Arquitetura) - Universidade de Brasília, Brasília, 1999.

SOARES, R. V.; BATISTA, A. C. Incêndios florestais: controle, efeitos e uso do fogo. Curitiba, 2007. $264 \mathrm{p}$.

Meteorologia e climatologia florestal. Curitiba, 2004. 195 p.

XAVIER, A. A. P. Condições de conforto térmico para estudantes de $\mathbf{2}^{\circ}$ grau na região de Florianópolis. 198 f. Dissertação (Mestrado em Engenharia Civil) - Universidade Federal de Santa Catarina, Florianópolis, 1999. 